\title{
The effect of ball milling on crystallite size
}

\author{
${ }^{* 1}$ Oguzhan Sahin and ${ }^{1}$ Veysel Erturun \\ ${ }^{* 1}$ Faculty of Aeronautics and Astronautics, Erciyes University, Turkey
}

\begin{abstract}
Homogeneous mixing of $\mathrm{Al}$, varying amounts of $\mathrm{Cu}, \mathrm{Mg}$ and $\mathrm{Zn}$ metal powders and $\mathrm{SiC}$ ceramic powders and mechanical alloys of metal powders by using high energy ball milling were carried out in the Retsch MM400 model mixer device, which performs movement in a spex manner. After this process, $\mathrm{X}$-ray diffraction (XRD) was applied to the powdered mixtures. With the data obtained from XRD graphics; The crystallite size was calculated using the Scherrer equation, and the lattice stresses were calculated using the Williamson-Hall equation and comparisons between these two data were made. It was observed that the amount of $\mathrm{Cu}$ by weight, both the crystallite size, did not make a notable change for this property. Then, powder mixtures were sintered in hot isostatic press in argon atmosphere, which is a shielding gas, and turned into samples. These samples were polished and scanning electron microscopy (SEM) images were taken.
\end{abstract}

Key words: Powder metallurgy, ball milling, mechanical alloying, characterization, metal matrix composite

\section{Introduction}

Today, the need for light and low-cost materials in many industry applications tends to increase steadily. In line with this trend, new and more modern techniques are tried to be created for the production of metal matrix composites (MMK). These techniques include mechanical alloying (MA), which plays an active role in bonding metal-metal or metal-ceramic materials together. MA is a solid-state powder processing technique that allows powder particles to break, weld and then break again. The MA process is carried out using ball milling [1]. It has been used in the synthesis and balancing of new intermediate phases from 1985 to 2001 and in new processes that have not been tried so far until today [2]. John Benjamin and his friends described the MA process, considered as part of powder metallurgy, as a method for producing composite metal powders with controlled fine microstructure [3]. With the MA technique, the crystallite size of the matrix powder can be reduced to nano levels. Aluminum matrix composites find wide adaptation areas due to their high wear resistance, high elastic modulus, high hardness and high tensile strength aspects [4]. Ceramic reinforced aluminum matrix composites are frequently used in industries such as automotive and aerospace. These composites are used in piston rods, brake discs and cylinder blocks in automotive applications, and wing covers in aviation applications [5].

In the study of S. Kamrani et al., the average particle size -325 mesh $\mathrm{Mg}$ and $50 \mathrm{~nm} \mathrm{SiC} \mathrm{powders}$ were first mixed in the Turbula T2C device for 20 minutes in a $2 \mathrm{wt} \%$ stearic acid environment. Then, in Pulverisette 5, a planetary ball mill, these powders were alloyed at $250 \mathrm{rpm}$ with zirconia

*Corresponding author: Address: Faculty of Aeronautics and Astronautics, Department of Aircraft Fuselage and Powerplant Maintenance Erciyes University, 38039, Kayseri TURKEY. E-mail address: oguzhansahin@erciyes.edu.tr, Phone: +905436400035 
balls in a polyethylene bottle for 1, 3, 5, 15, 20 and 25 hours. In this process, 10: 1 was used as the ball to powder weight ratio. They carried out all operations in an argon shielding gas atmosphere. They obtained the crystallite size in the Mg matrix from XRD peak broadening. As a result of this study, they showed that crystallite size decreased with increasing alloying time and $\mathrm{SiC}$ amount [6].

In the study of L. Litynska-Dobrzynska et al, Al-12 wt\% Zn-3 wt\% Mg-1.5 wt\% Cu composition ball milled in planetary ball mill by adding $1 \mathrm{wt} \%$ and $2 \mathrm{wt} \% \mathrm{Zr}$ powder. Ball milling was carried out in argon atmosphere with steel balls and ball to powder weight ratio was 10:1. As a result, it leads to a homogeneous mixture of approximately $100 \mathrm{~nm}$ grain size nanocrystalline aluminum solid solution after 80 hours of milling. $\mathrm{Zr}$ and $\mathrm{Cu}$ rich particles of the fcc structure are defined in powders containing $\mathrm{Zr}$ [7].

In the study of Indranil Lahiri and Sanjeev Bhargava, $\mathrm{Cu} 10 \mathrm{wt} \% \mathrm{Cr}$ and $\mathrm{Cu} 50 \mathrm{wt} \% \mathrm{Cr}$ alloyed two different compositions in a Pulverisette 5 planetary ball grinder at $200 \mathrm{rpm}$ at different times such as $5 \mathrm{~min}, 1 \mathrm{~h}, 10 \mathrm{~h}, 50 \mathrm{~h}$ and $150 \mathrm{~h}$. While doing this, 5 steel balls having $25 \mathrm{~mm}$ diameter with ball to powder ratio 8:1 were used. In their study, they made a crystallite size comparison with the data obtained from XRD peaks. According to the results of their studies, crystallite size decreases with the increase of alloying time [8].

M. Rabiee et al. used pure $\mathrm{Fe}(<150 \mu \mathrm{m})$, pure $\mathrm{Cu}(<150 \mu \mathrm{m})$ and $\mathrm{SiC}(<12 \mu \mathrm{m})$ powders as alloying elements. Then $\mathrm{Cu}-20 \mathrm{wt} \% \mathrm{Fe}$ composition was alloyed for 20 hours, by adding $3 \mathrm{wt} \% \mathrm{SiC}$ and 5 $\mathrm{wt} \% \mathrm{SiC}$ alloyed for a further 5 hours in a planetary

ball mill with hardened steel vial and balls under argon atmosphere. With XRD investigation the crystallite size of $\mathrm{Cu}$ decreased by increasing milling time and the addition of $\mathrm{SiC}$ decreased the crystallite size [9].

In this study, it is aimed to mechanically produce and characterize an alloy similar to aluminum 2024 alloy with a device with spex operating logic.

\section{Materials and Method}

Provide the purity, weight ratios and grain sizes of metal powders and ceramic powder used to produce composite materials with MA treatment in the composition are given in Table 1.

Table 1. Features of Used Powders

\begin{tabular}{cccccc}
\hline \multirow{2}{*}{$\begin{array}{c}\text { Sample } \\
\text { name }\end{array}$} & \multicolumn{5}{c}{ Participation Rate of Powders by Weight } \\
\cline { 2 - 5 } $\mathrm{Al}(7 \mu \mathrm{m})$ & $\mathrm{Zn}(7 \mu \mathrm{m})$ & $\mathrm{Mg}(45 \mu \mathrm{m})$ & $\mathrm{Cu}(7 \mu \mathrm{m})$ & $\mathrm{SiC}(7 \mu \mathrm{m})$ \\
\hline $\mathrm{A}$ & $93,2 \%$ & $0,3 \%$ & $1,5 \%$ & $0 \%$ & $5 \%$ \\
$\mathrm{~B}$ & $90,2 \%$ & $0,3 \%$ & $1,5 \%$ & $3 \%$ & $5 \%$ \\
$\mathrm{C}$ & $88,2 \%$ & $0,3 \%$ & $1,5 \%$ & $5 \%$ & $5 \%$ \\
\hline
\end{tabular}


These powders were placed in $120 \mathrm{~mm}^{3}$ thermoset plastic bottles with the weight ratios in Table 1 , filling $25 \%$ of the volume. 454 steel balls with a diameter of $3 \mathrm{~mm}$ were placed in the same bottle, filling $50 \%$ of the bottle volume. The ball / powder weight ratio was applied at a value of 10 . The reason why these numbers are chosen in this way is that they are the values of the best milling and alloying [1].

The bottles were filled with argon gas to prevent oxidation after the powders were placed. The prepared bottles were alloyed on the Retsch MM400 model device at a frequency of $15 \mathrm{~Hz}$ for 90 minutes. Before sintering, some amount was taken from the powder mixtures for XRD analysis. The mold parts were coated with Sogerver SP 500 graphite lubricant to prevent sticking of the mold parts and sample before sintering. Sintering process was carried out at $600^{\circ} \mathrm{C}$ for 20 minutes at $200 \mathrm{MPa}$ pressure. After sintering, solid samples were polished to obtain SEM images. The XRD graphic of the samples is shown in Figure 1.

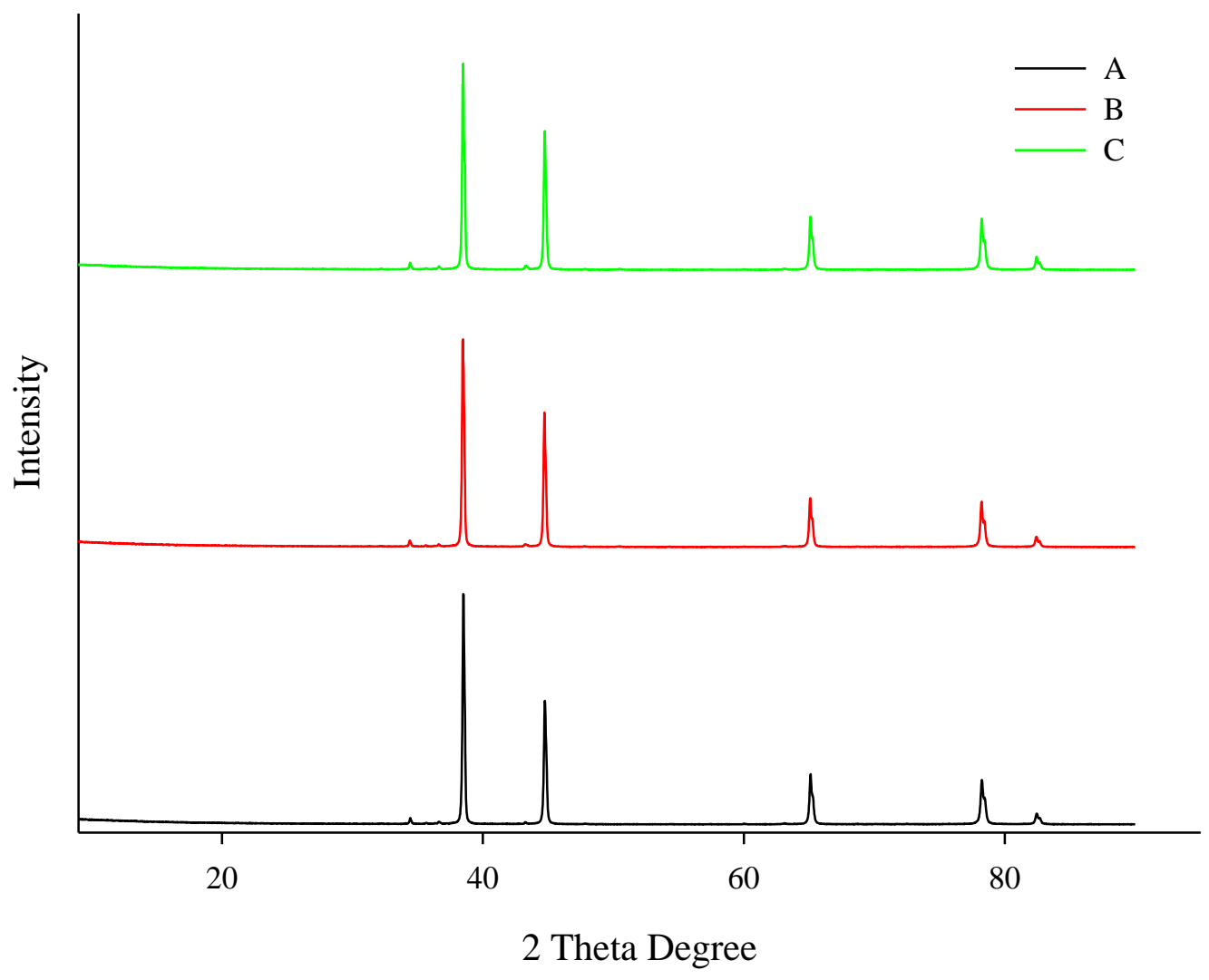

Figure 1. XRD graph of samples

When Figure 1 is examined, the increase in the amount of $\mathrm{Cu}$ in the composition based on the highest grade Al peaks caused shorter lengths and widening in the peaks. In Figure 2, SEM images of powder mixtures before alloying are given. 


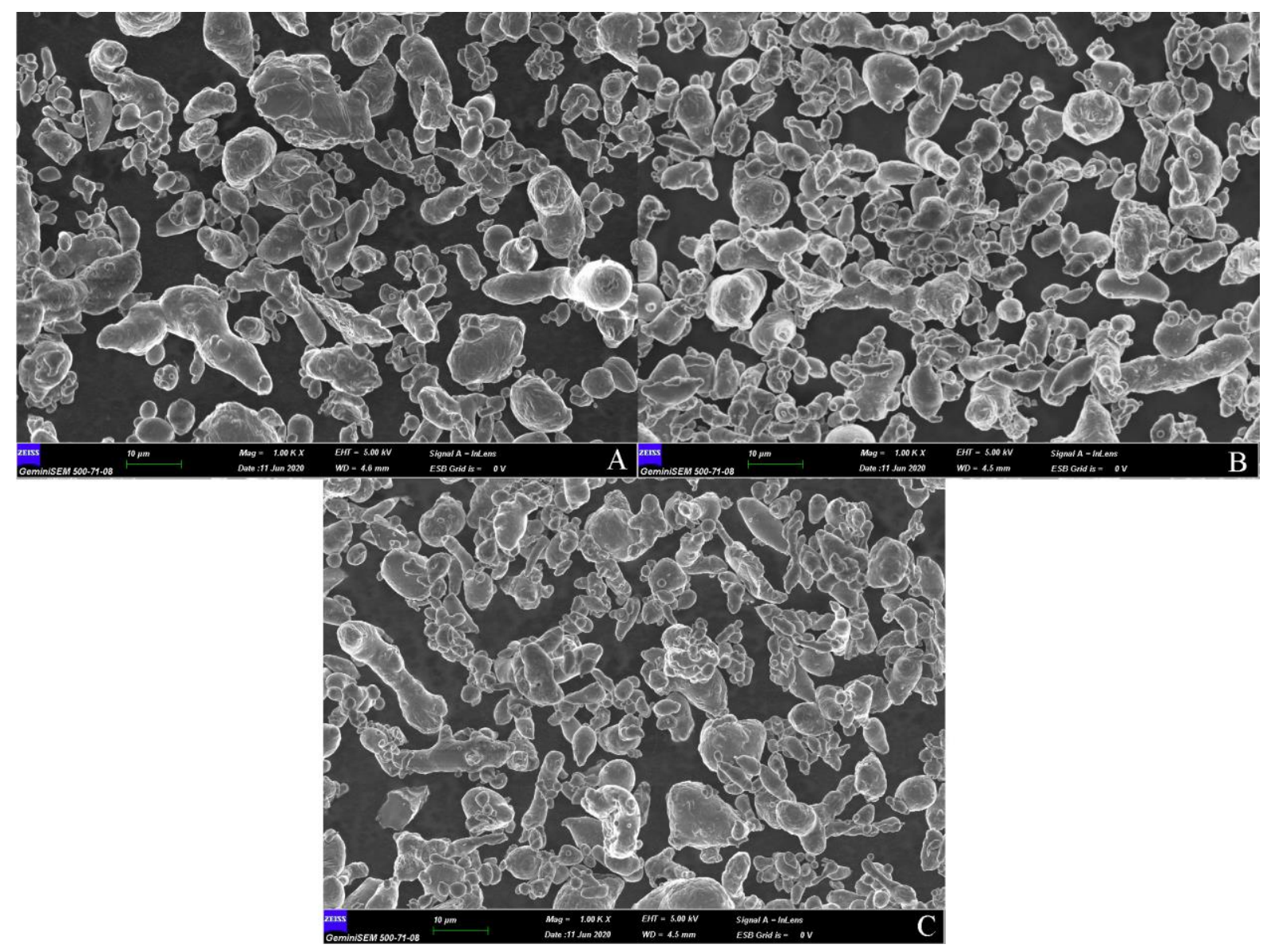

Fig. 1 SEM images of powder mixtures before alloying

When Figure 2 is examined, almost identical images with containing round grains are seen. Other elements gathered around coarse grained $\mathrm{Mg}$ can be seen. $\mathrm{SiC}$ grains are in a separate powder composition without being integrated with the structure. In Figure 3, SEM images of powder mixtures that are alloyed for 90 minutes are given. 


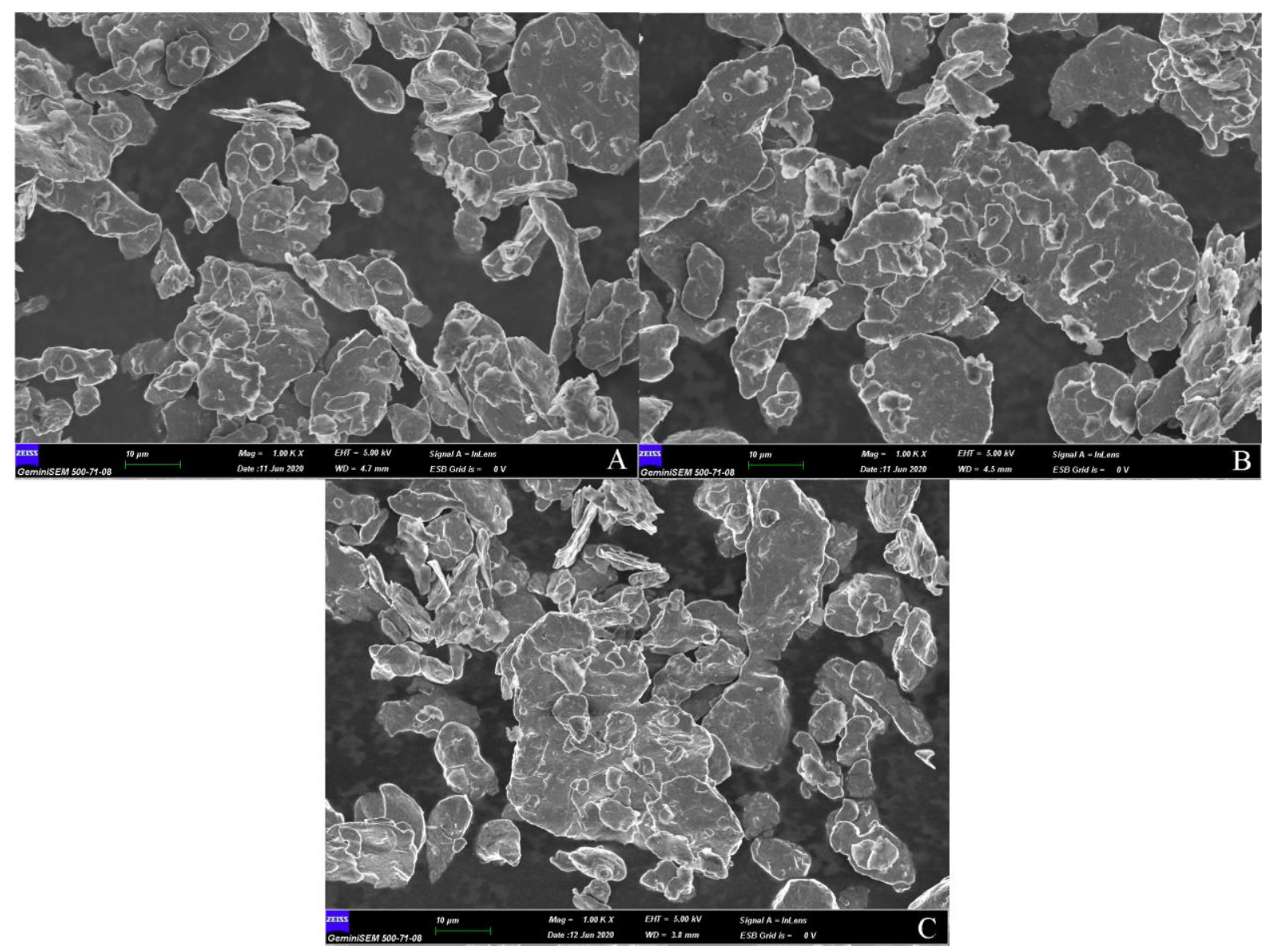

Fig. 3 SEM images of alloyed powder mixtures

When Figure 3 is examined, it is seen that the $\mathrm{C}$ sample containing $5 \% \mathrm{Cu}$ is in the pulpy structure. In addition, agglomerates have formed in all sample powders. According to Figure 2, rounded grains turned into flakes. SiC grains are integrated with the structure.

$$
\mathrm{d}=\mathrm{k} \lambda /(\beta \cos \theta)
$$

In this equation, $d$ refers to crystal size, $k$ is the shape factor between 0 and $1(k=0,9), \lambda$ refers to $\mathrm{XRD}$ wavelength, $\beta$ refers to full width at half height of the maximum diffraction peak and $\theta$ refers to diffraction angle.

Figure 4 shows the crystallite size of the samples using the data obtained from the XRD graph. Crystallite dimensions were calculated using Scherrer equation (equation 1) [6]. 


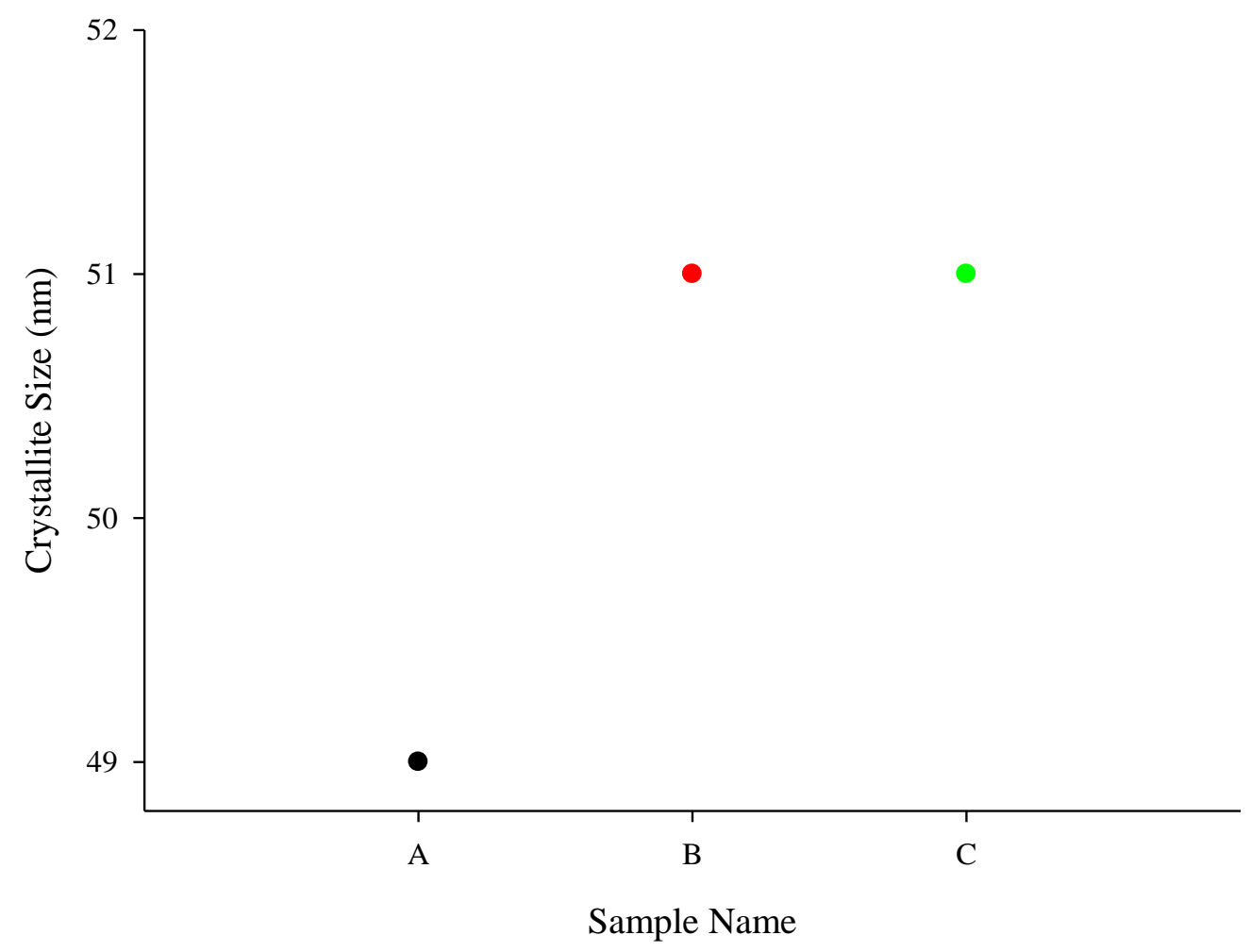

Fig. 4 Crystallite size of samples

When Figure 4 is examined, it is seen that crystallite size decreases with the $\mathrm{Cu}$ amount from $0 \%$ to $3 \%$ by weight in the powder composition and the crystallite size does not change after $3 \%$. According to these data taken from $\mathrm{Al}$ peaks, it was observed that $\mathrm{Cu}$ particles welded to $\mathrm{Al}$ particles with $3 \%$ by weight $\mathrm{Cu}$ addition, but this welding did not occur $3 \%$ by weight.

\section{Conclusions}

When the XRD graph is analyzed, the highest grade $\mathrm{Al}$ peak length of the alloy with $3 \% \mathrm{Cu}$ by weight has decreased compared to the alloy with $0 \% \mathrm{Cu}$ by weight. However, $3 \% \mathrm{Cu}$ by weight, there was no reduction in Al peak lengths.

When the SEM images of the samples were examined, the Al particles, which are the matrix element, were in round shape before alloying, and then became scaly and flat after alloying. It has been observed that $\mathrm{SiC}$ particles enter the matrix and take on an integrated structure.

When the crystallite sizes of the samples were calculated, the amount of $\mathrm{Cu}$ increased from $0 \%$ to $3 \%$, the crystallite size increased slightly, but the increase in the amount of $\mathrm{Cu}$ more weight did not 
change the crystallite size.

\section{Acknowledgements}

The authors would like to thank the Erciyes University Scientific Research Unit for supporting this work with project number FBA-2018-8068

\section{References}

[1] German RM. Powder Metallurgy \& Particulate Materials Processing, Metal Powder Industries Federation, 2005.

[2] Suryanaryana C. Recent developments in mechanical alloying. Rev Adv Mater Sci 2008;18:203-11.

[3] El-Eskandarany MS. Structural evolution of rod milled $\mathrm{Cu} 2 \mathrm{O}$ and $\mathrm{Ti}$ powders during mechanical solid state reduction. Mater Trans 1995;36:182-7.

[4] Özyürek D, Tekeli S, Güral A, Meyveci A and Gürü M. Effect of Al2O3 amount on microstructure and wear properties of Al-A12O3 metal matrix composites prepared using mechanical alloying method. Powder Metall Met Ceram 2010;49:289-94.

[5] Azimi A, Shokuhfar A and Zolriasatein A. Nanostructured Al-Zn-Mg-Cu-Zr alloy prepared by mechanical alloying followed by hot pressing. 2014;595:124-30.

[6] Kamrani S, Penther A, Ghasemi R and Fleck C. Microstructural characterization of Mg-SiC nanocomposite synthesized by high energy ball milling. Adv Powder Technol 2018;29:174248 .

[7] Litynska-Dobrzynska L, Dutkiewicz J, Maziarz W and Góral A. The effect of zirconium addition on microstructure and properties of ball milled and hot compacted powder of Al-12 wt\% Zn-3 wt\% Mg-1.5 wt\% Cu alloy. J Alloys Compd 2011;509:S304-8.

[8] Lahiri L and Bhargava S. Crystallite size of mechanically alloyed $\mathrm{Cu}-\mathrm{Cr}$ powder - A comparison between X-ray diffraction and atomic force microscopy techniques. Mater Charact 2009;60:1406-10.

[9] Rabiee M, Mirzadeh $\mathrm{H}$ and Ataie A. Processing of $\mathrm{Cu}-\mathrm{Fe}$ and $\mathrm{Cu}-\mathrm{Fe}-\mathrm{SiC}$ nanocomposites by mechanical alloying. Adv Powder Technol 2017;28:1882-87. 